\title{
Estimated Prevalence of Sickle Cell in Northern Haiti
}

\section{TIM R RANDOLPH}

OBJECTIVE: The purpose of this study is to estimate the prevalence of sickle hemoglobin in northern Haiti.

DESIGN: Sickle cell testing occurred from 2002-2009. Blood samples from 1035 subjects were collected for diagnostic purposes, de-identified, and made available for the study.

SETTING: Bethesda Medical Center and Eben-Ezer Clinic in northern Haiti.

SUBJECTS: Study subjects included prenatal patients, their companions, clinic staff and volunteers. All subjects were Haitian and selected to most closely represent healthy patients present at the clinic. Deidentification of the blood samples precluded the need for informed consent.

MAIN OUTCOME MEASURES: Each subject was tested for sickle hemoglobin using a standard hemoglobin solubility test and results were recorded as either positive or negative.

RESULTS: The estimated prevalence of sickle hemoglobin was $15.1 \%$ with a $95 \%$ confidence interval of $12.2-18 \%$.

CONCLUSIONS: These prevalence rates validate the clinical significance of sickle cell disorder, help guide clinical decisions, and suggest the need to develop intervention programs among the people of northern Haiti.

ABBREVIATIONS: SS = Homozygous for the sickle cell gene; AS = Heterozygous for the sickle cell gene; SCD = Sickle cell disease (homozygous) SCT = Sickle cell trait (heterozygous).
INDEX TERMS: Sickle cell; anemia; Haiti; beta globin; mutation

Clin Lab Sci 2010;23(2):79

Tim R. Randolph, PhD, CLS(NCA), Saint Louis University, St. Louis, MO 63104-1111

Address for Correspondence: Tim R. Randolph, PhD, CLS(NCA), Department of Clinical Laboratory Science, Doisy College of Health Sciences, Saint Louis University, 3437 Caroline St., St. Louis, MO 631041111,randoltr@slu.edu

\section{INTRODUCTION}

Haiti is a small country in the northern Caribbean Sea that is often considered the poorest country in the Western Hemisphere and one of the most economically disadvantaged countries in the world. ${ }^{1-3}$ Haiti shares the island of Hispaniola with the Dominican Republic. Haiti occupies the western third of the island and the Dominican Republic, the eastern two thirds. The Haitian people are of black African descent initially arriving in Haiti as slaves to the French in the 1600s. ${ }^{4}$ Although the life expectancy of the average Haitian has risen from 49.6 years in the mid-1990s to 55 years in 2006, these data can be improved. ${ }^{3}$

The health care system in Haiti is poorly regulated and severely under funded. Medical services are provided by one of three types of facilities; governmental hospitals, private for-profit clinics, and charity-run facilities that are predominantly associated with religious organizations. The Haitian government has been unsuccessful at creating an infrastructure so most clinics operate with no running water and inadequate electricity. The majority of clinics with electricity operate their own generators that are too small for the 


\section{RESEARCH AND REPORTS}

electrical demand and are often in disrepair or sitting idle due to insufficient funds to purchase fuel. Many rural clinics do not own a generator and either function without power or use exclusively solar energy. As a result, Haitian clinics are functioning at suboptimal levels due primarily to a lack of infrastructure, medical resources, and adequately trained personnel. ${ }^{4}$

In addition to these deficiencies, there is a paucity of published medical information on many prominent medical conditions in Haiti. Ongoing research is necessary to guide clinical practice and to justify the development of therapeutic intervention programs to improve patient outcomes. One prominent example is sickle cell anemia. Based on a comprehensive search of the medical literature using Medline and PubMed during the timeframe of 1950 to the present, five manuscripts were discovered with a focus on sickle cell anemia in Haiti. Of these five manuscripts, three studies involved children of Haitian descent living in New York and Miami. ${ }^{5-7}$ Of these three reports, only one estimated the prevalence of sickle cell trait (AS) in Haiti as $8 \%$ based on testing Haitian immigrants in Miami. $^{7}$ The two remaining manuscripts were written in French; one of which was in the form of a letter published by Molez JF, et. al. in 1995 and the other was a case report by De Caluwe JP et. al. in 1993. ${ }^{8,9}$ The De Caluwe manuscript described 19 AC heterozygotes and 5 SC compound heterozygotes in which Haitian subjects were the least represented and no prevalence data was reported. ${ }^{9}$ The Molez group tested 2,114 patients for sickle hemoglobin between 1980 and 1986 and reported a prevalence that ranged from $7.94 \%$ to $19.23 \%$ with a mean percentage of $13.0 \%{ }^{8}$ The paper also cited four additional authors, three published and one unpublished, who report a prevalence of sickle cell homozygotes ranging from $0 \%$ to $7.5 \%$ and heterozygotes from $6.9 \%$ to $28.3 \%$ as determined by alkaline hemoglobin electrophoresis. All four authors also report the prevalence of hemoglobin $\mathrm{C}$ heterozygotes (AC) between $2.8 \%$ and $5.9 \%$ and hemoglobin $\mathrm{S}$ and $\mathrm{C}$ compound heterozygotes (SC) between $0 \%$ and $0.3 \% .{ }^{8}$ Lastly, a Google search found one unpublished report from 1984 by Estelle Dubuisson of the Friends of the Children of Lascahobas Haiti Foundation who tested Haitian patients for sickle hemoglobin and found a $24 \%$ heterozygous prevalence and $2 \%$ with homozygous disease. ${ }^{10}$ The paucity of biomedical reports relating to sickle cell disease in Haiti under represents the impact of the disease on the Haitian people and the need for successful on-going intervention programs in Haiti. In addition, the wide range of prevalence rates reported in the medical literature does not provide a clear representation of the disease to practicing physicians. One approach to improving the delivery of medical services in Haiti is to collect and disseminate incidence and prevalence rates of endemic diseases to empower health care providers with information to guide clinical practice. To that end, this study reports estimated prevalence rates of sickle hemoglobin in the northern sector of Haiti.

\section{MATERIALS AND METHODS}

Research Design. Free mass screening for sickle hemoglobin was performed for eight consecutive years (2002-2009) at Bethesda Medical Center and EbenEzer Clinic in northern Haiti, during an annual medical mission trip. Bethesda Medical Center and Eben-Ezer Clinic are located in the northern sector of Haiti, a few miles south of the second largest city of Cap-Haitien.

Patient Population. Subjects were selected for the study based on a sample of convenience from patients visiting Bethesda Medical Center and Eben-Ezer Clinic in northern Haiti. The majority of the subjects represented healthy women visiting the clinic for prenatal checkups while the rest were clinic staff, individuals accompanying patients to the clinic, and random volunteers.

Sickle Cell Screening. Testing was performed using the hemoglobin solubility method (Chembio Diagnostics Systems, Inc. Medford, NY) which detects the presence of sickle hemoglobin but cannot distinguish heterozygous sickle cell trait (SCT) from the homozygous sickle cell diseases (SCD). Using this procedure, whole blood is placed in a solution containing a detergent based lysing agent (Saponin), a reducing agent (sodium hydrosulfite), and a phosphate buffer solution. The RBCs are lysed to release the hemoglobin, which is reduced to the deoxygenated form and exposed to the phosphate buffer. In the deoxyhemoglobin form, hemoglobin $\mathrm{A}$ is soluble yielding a clear solution, while hemoglobin $S$ 


\section{RESEARCH AND REPORTS}

polymerizes becoming insoluble producing turbidity. Turbidity of the sample is a positive test result and indicates the presence of insoluble hemoglobin $S$, or other rare insoluble hemoglobin variants to include HbC Georgetown (Harlem), HbC Ziguinchor, HbS Memphis, HbS Travis, HbS Antilles, HbS Providence, HbS Oman, $\mathrm{Hb}$ Alexander, Hb Porte-Alegre. ${ }^{11}$

\section{RESULTS}

Sickle Cell. Between 2002 and 2009 a total of 1035 patients were tested for sickle hemoglobin, 769 females and 266 males. Among the 769 females, 407 (52.9\%) were pregnant and visiting the clinic for routine prenatal screening. Of the remaining 628 patients, 412 were clinic patients, 70 subjects were healthy companions of clinic patients, 33 were clinic staff and 113 were random volunteers from the community. In total, 623 of the 1035 subjects were healthy individuals representing $60.2 \%$ of the test population. Of the 1035 total subjects tested, 160 tested positive for sickle hemoglobin yielding a prevalence rate of $15.5 \%$ with a $95 \%$ confidence interval of $12.2-18 \%$. (Table 1 ) The laboratory staff was instructed to check the testing log sheets from previous years to avoid duplicate subjects.

\section{DISCUSSION}

In the Haitian culture it is very difficult to recruit healthy volunteers to constitute a random sample for a variety of reasons. Many Haitians fear that the removal of blood is detrimental to their health. Since disease is so common and often fatal, Haitians who are not ill will not donate for fear of becoming ill. This is especially true when blood is being collected by venipuncture compared to capillary puncture since venipuncture removes a larger volume of blood. Additionally, recruitment incentives like food or currency can attract masses of volunteers potentially creating chaos and safety issues, especially when the recruitment incentives are exhausted. Unfortunately, prevalence data could be skewed if samples are collected exclusively from symptomatic patients seeking medical attention at the clinic. Three strategies were used to minimize the effect of non random sampling to obtain an acceptable sample. First, testing was offered free of charge to encourage participation of as many subjects as possible. Second, testing was performed primarily on prenatal clinic days where the patient population was predominantly healthy pregnant women. Third, testing was offered to the clinic staff and to the companions of clinic patients who were not seeking medical attention. Lastly, some individuals from the community heard about the free screening program and volunteered. Although this does not represent a random sampling approach, given the circumstances these strategies are designed to approximate a random sample.

The estimated prevalence of sickle hemoglobin in northern Haiti reported here (15.4\%) is similar to rates previously published that range between $8 \%$ and $29.7 \%$. $^{6}, 8-10 \quad$ However, ranges of between $8 \%$ and $29.7 \%$ do not provide a clinically useful estimate of the prevalence a physician should expect among clinic patients. A more reliable prediction of the frequency at which patients with sickle hemoglobin will enter the clinic is useful in making good clinical decisions.

Through many personal experiences in Haiti the author has observed several problems regarding the identification of sickle hemoglobin and the differentiation of sickle heterozygotes from homozygotes. Many Haitian clinic labs have no method of identifying sickle hemoglobin. Among the clinic labs who offer sickle cell testing, the methods are antiquated and prone to producing false negative and positive results. The most unreliable method observed involves tying a rubber band around the finger tip to create a hypoxic environment in hopes of generating sickle cells that can be identified on a microscope slide. Inability to create a hypoxic environment sufficient to convert oxyhemoglobin to deoxyhemoglobin in the fingertip will result in the absence of sickle cell formation and a false negative test result. The sodium metabisulfite test is the most common method of sickle cell testing in Haiti. In this method, the reducing agent, sodium metabisulfite is added to a drop of patient blood on a microscope slide. The mixture is covered with a coverslip and sealed with Vaseline or fingernail polish to prevent the exchange of oxygen with the outside environment. The sodium metabisulfite converts the hemoglobin to the deoxygenated form, predisposing the RBCs bearing the sickle hemoglobin to form sickle cells that can be observed under the microscope. Insufficient incubation or leaks around the coverslip will prevent sickle cell formation resulting in a 
Table 1. Prevalence of Sickle Cell in Northern Haiti Between 2002-2007

\begin{tabular}{|c|c|c|c|c|c|c|}
\hline Year & Patients & Mean Age & Gender & Pregnancy & Positive & Prevalence \\
\hline 2002 & 61 & $33.7^{\circ}$ & $\begin{array}{l}54 \text { female } \\
7 \text { male }\end{array}$ & 31 pregnant & 9 & $14.8 \%$ \\
\hline 2003 & 66 & 27.5 & $\begin{array}{l}65 \text { female } \\
1 \text { male }\end{array}$ & 65 pregnant & 16 & $24 \%$ \\
\hline 2004 & 53 & 26 & $\begin{array}{l}42 \text { female } \\
11 \text { male }\end{array}$ & 42 pregnant & 14 & $26 \%$ \\
\hline 2005 & 143 & 29.5 & $\begin{array}{l}113 \text { female } \\
30 \text { male }\end{array}$ & 61 pregnant & 15 & $10.5 \%$ \\
\hline 2006 & 54 & 32.7 & $\begin{array}{l}33 \text { female } \\
21 \text { male }\end{array}$ & 28 pregnant & 4 & $7.4 \%$ \\
\hline 2007 & 41 & 30.6 & $\begin{array}{c}23 \text { female } \\
18 \text { male }\end{array}$ & 20 pregnant & 5 & $12 \%$ \\
\hline 2008 & 199 & 33.4 & $\begin{array}{l}127 \text { female } \\
72 \text { male }\end{array}$ & 87 pregnant & 37 & $18.6 \%$ \\
\hline 2009 & 418 & 31.8 & $\begin{array}{l}312 \text { female } \\
106 \text { males }\end{array}$ & 73 pregnant & 60 & $14.4 \%$ \\
\hline TOTAL & 1035 & 31.3 & $\begin{array}{l}769 \text { female } \\
266 \text { male }\end{array}$ & 407 pregnant & 160 & $15.5 \%$ \\
\hline
\end{tabular}

false negative result. False negative or false positive results can be produced by both methods when performed by inexperienced laboratory personnel since the identification of sickle cells requires independent judgment.

Based on personal communications with three physicians practicing full-time in Haitian clinics that are serviced by the author, the frequency of patients with vaso-occlusive symptoms suggestive of sickle cell disease are much less frequent than the published incidence rates would suggest. A likely explanation is that since most clinic labs have either no method or only unreliable methods of identifying sickle hemoglobin and none of the methods described here can determine zygosity, patients are less aware of the condition and probably die before seeking medical attention.

\section{CONCLUSION}

Scientific papers in the biomedical literature relating to sickle cell anemia in Haiti are sparse, outdated, and report highly variable results. In the absence of medical information, physicians are unable to reliably predict the frequency at which diseases like sickle cell will occur in their clinics. Physicians can not order sickle cell testing that does not exist and the unreliable methods used in Haitian labs may produce false negative results reducing the perception of the frequency of the disease and thus its importance. Patients and physicians will become less aware of these diseases and patients with sickle cell disease will be less likely to seek medical attention. Based on these observations the author hypothesizes that many Haitian patients die of sickle cell disease at a very young age without seeking medical attention. The prevalence rate of $15.4 \%$ reported here helps to clarify for physicians the importance of this disease and to justify the need for better testing methods and intervention programs to extend survival rates and improve patient outcomes.

\section{REFERENCES}

1. Dupuy A. Haiti in the world economy: class, race and underdevelopment. Boulder, CO: Westview Press. 1989.

2. Fatton R. Haiti's Preditory Republic: The unending transition to democracy. Boulder, CO: Lynne Rienner Publisher. 2002.

3. World Health Statistics. Part 2: World Health Statistics. World Health Organization. 20 Avenue Appia, 1211 Geneva 27, Switzerland. Printed in France. 2006.

4. Arthur, Charles. Haiti in Focus: A Guide to the People, Politics, and Culture. New York:Interlink Books; 2002.

5. Rey KS, Unger CA, Rao SP, et. al. Sickle cell-hemoglobin E disease: Clinical findings and implications. Journal of Pediatrics. 1991;119(6):949-51.

6. Pegelow $\mathrm{CH}$. Increased incidence of bacteremia in Haitian children with sickle cell anemia. Southern Medical Journal. 1989;82(7):833-6.

7. Pegelow $\mathrm{CH}$ and Mack $\mathrm{AK}$. Incidence of hemoglobins $\mathrm{S}$ and $\mathrm{C}$ in infants born in Miami to recent Haitian immigrants. Trop Geogr Med. 1989;41(4):316-9. 


\section{RESEARCH AND REPORTS}

8. Molez JF. Henrys JH. Boncy J. et. al. Note on hemoglobins encountered in Haiti. Medecine Tropicale. 1995;55(4):391.

9. De Caluwe JP. Alexander M. Bondue H. Hemoglobin C (alpha 2 beta 2 6Glu-->lys). Study of 19 heterozygote AC carriers and of 5 cases of double hemoglobinopathy SC. Acta Clinica Belgica. 1993;48(5):297-306.
10. Dubuisson, E. Haiti Health Facts. http://www.fclh.org/facts/ index.htm 1984.

11. Randolph TR. Hemoglobinopathies (Structural Defects in Hemoglobin). In Rodak BF, Fritsma GA, and Doig K (eds.):Hematology: Clinical Principles and Applications, 3rd ed, St. Louis: Saunders, Elsevier, 2007:333-54.

The peer-reviewed Research and Reports Section seeks to publish reports of original research related to the clinical laboratory or one or more subspecialties, as well as information on important clinical laboratory-related topics such as technological, clinical, and experimental advances and innovations. Literature reviews are also included. Direct all inquiries to David $L$ McGlasson MS, MLS, 59th Clinical Research Division/SGRL, 2200Berquist Dr., Bldg. 4430, Lackland AFB TX $78236-$ 9908, david.mcglasson@lackland.af.mil

Clinical Laboratory Science encourages readers to respond with thoughts, questions, or comments regarding these articles. Email responses towestminsterpublishers@comcast.net. In the subject line, please type the journal issue and lead author such as "CLIN LAB SCI 23(2) RE RANDOLPH". Selected responses may appear in the Dialogue and Discussion section in a future issue. Responses may be edited for length and clarity. We look forward to hearing from you. 